\title{
Características morfoanatômicas da epiderme foliar de plantas variantes e não variantes somaclonais de bananeiras (Musa sp. Colla cv. Prata-anã) cultivadas in vitro ${ }^{1}$
}

\author{
Guilherme Araújo Lacerda ${ }^{2,4}$, Janaina de Oliveira Costa e Silva ${ }^{3}$, Juscélio Clemente de Abreu², \\ Eduardo Alves ${ }^{3}$ e Luciano Vilela Paiva ${ }^{3}$
}

Recebido em 8/12/2006. Aceito em 2/05/2007

\begin{abstract}
RESUMO - (Características morfoanatômicas da epiderme foliar de plantas variantes e não variantes somaclonais de bananeiras (Musa sp. Colla cv. Prata-anã) cultivadas in vitro). A variação somaclonal corresponde ao aparecimento de plantas anormais durante o processo de multiplicação in vitro, principalmente relacionada à estatura, no caso o gigantismo. O objetivo deste trabalho foi averiguar as diferenças morfoanatômicas da epiderme foliar na tentativa de diferenciar as plantas de 'Prata-anã' em relação aos seus variantes somaclonais. A análise por microscopia eletrônica de varredura mostrou uma diferença significativa entre o diâmetro polar dos estômatos da 'Prata-anã' não variante e suas variantes, ambas em condições in vitro, observando-se que o mesmo não ocorre para as plantas in vivo. O número médio de estômatos é menor nas plantas variantes somaclonais, porém sem diferenças significativas a não ser para a planta PIII. A descamação de cera é evidente somente nas plantas variantes de ambos os materiais (in vitro e in vivo). Conclui-se que os caracteres morfoanatômicos da epiderme foliar, como densidade estomática, diâmetro estomático polar e a uniformidade da cera atuam como marcadores morfológicos para caracterizar as plantas micropropagadas de 'Prata-anã' em relação aos seus variantes somaclonais para a característica gigantismo.
\end{abstract}

Palavras-chave: cera, estômato, banana

ABSTRACT - (Morphoanatomical characteristics of the leaf epidermis of variant plants and somaclonal non-variants of banana trees (Musa sp. Colla cv. Prata-anã) cultivated in vitro). Somaclonal variation corresponds to the emergence of abnormal plants during the process of multiplication in vitro, mainly related to stature, in the case the gigantism. The aim of this work was to discover morphoanatomical differences of the leaf epidermis in an attempt to differentiate plants of "Prata-anã" from their somaclonal variants. Analysis by scanning electronic microscopy showed significant difference between the polar diameter of the stomata of the "Prata-anã" non-variant and its variants, both in vitro. The same does not happen for plants in vivo. The average number of stomata is lower in the somaclonal variant plants, but without significant differences except for plant PIII. Wax peeling is only evident in the variant plants of both the in vitro and in vivo material. We concluded that morphoanatomical characters of the leaf epidermis, such as stomatal density, polar stomatal diameter and wax uniformity act as morphological markers to characterize the micropropagated plants of "Prata-anã" in relation to the somaclonal variants for the characteristic gigantism.

Key words: wax, stomata, banana

\section{Introdução}

A qualidade da muda é imprescindível para o bom desempenho da cultura da banana. As mudas devem ser provenientes de plantas vigorosas, sadias, produtivas, com cachos bem formados, sistema radicular bem desenvolvido, rizoma e raízes sem necrose de broca e isento de nematóides (Souto et al. 1997). A micropropagação surge como uma alternativa para produção de mudas de melhor qualidade. Porém, existem problemas na micropropagação como: (1) Contaminação das culturas durante a fase in vitro, causada por fungos e bactérias; (2) Escurecimento dos explantes, causada pela oxidação polifenólica e (3) Variação somaclonal, pelo aparecimento de plantas anormais, as quais não correspondem geneticamente à planta-mãe (Souza et al. 1999) que tem sido o principal alvo de críticas desta técnica.

Com a utilização da técnica de micropropagação, mudas de bananeiras provenientes de cultura de tecidos

\footnotetext{
1 Parte da dissertação de Mestrado do primeiro Autor

2 Universidade Vale do Rio Verde, Avenida Castelo Branco 82, Chácara das Rosas, 37410-000 Três Corações, MG, Brasil

3 Universidade Federal de Lavras, Departamentos de Biologia, Fitopatologia e Química, C. Postal 3037, 37200-000 Lavras, MG, Brasil

4 Autor para correspondência: guilhermebiotecnologia@ig.com.br
} 
são produzidas e colocadas à disposição do agricultor. Ainda hoje, a falta de domínio completo dessa tecnologia pode levar a disponibilização no mercado de mudas de qualidade duvidosa, trazendo prejuízos aos agricultores devido à ocorrência de variantes somaclonais (Santos \& Rodrigues 2004).

$\mathrm{O}$ aparecimento de calos em determinada fase durante o cultivo in vitro, assim como períodos prolongados em meio de cultura são fatores que influenciam a taxa de variação somaclonal no processo de micropropagação (Santos \& Rodrigues 2004).

Além desses fatores, Smith (1988), inclui a propagação assexuada, a instabilidade genética e a composição do meio de cultura como determinantes da ocorrência de variação somaclonal. Este mesmo autor menciona a característica do gigantismo como ocorrência de variação somaclonal ao tratar-se da altura excessiva da planta devida à longa distância do ponto de emergência da folha (estiolamento).

Para identificação de variantes somaclonais da bananeira 'Prata-anã' cultivadas em um bananal na cidade de Andradas, MG, alguns parâmetros morfológicos foram utilizados como: folhas lanceoladas, porte mais alto, folhas mais eretas e pseudocaule mais fino nas plantas variantes (Guimarães 2005, dados não publicados).

Para averiguar a taxa de variação somaclonal entre bananeiras micropropagadas e aquelas propagadas vegetativamente, Álvares \& Caldas (2002), observaram que a 'Prata-anã' micropropagada foi significativamente superior quanto às variáveis: altura da planta, comprimento e largura da folha e pecíolo até o $15^{\circ}$ mês pós-plantio (fase de florescimento) em relação às plantas propagadas de forma convencional. Estes mesmos autores verificaram que $1 \%$ das bananeiras 'Prata-anã' micropropagadas eram gigantes (110 $\mathrm{cm}$ mais altas do que as plantas normais) e $0,5 \%$ apresentavam deformações nos cachos. Apenas os variantes somaclonais com folhas variegadas puderam ser identificados nos estádios iniciais de desenvolvimento. No entanto para a cultivar "New Guinea Cavendish" Damasco et al. (1996), observaram a ocorrência de variação somaclonal como resultante de plantas possuindo fenótipos deletérios, sendo mais freqüentemente, o nanismo.

Quando estas plantas são encontradas no campo, os danos já ocorreram e o prejuízo é inevitável. Algumas pesquisas têm sido realizadas para detectar precocemente a presença de variantes em mudas. De acordo com N. Guimarães, dados não publicados, comparou-se o crescimento de plantas variantes e normais de 'Prata-anã', durante o período de três meses em casa de vegetação, constatando que as plantas variantes já apresentavam uma altura maior, embora as condições de luminosidade, irrigação, temperatura e substrato fossem as mesmas para as plantas variantes e normais. Assim se confirmou a eficiência na seleção daquelas plantas que seriam variantes ou normais, porém o período de três meses para a confirmação é considerado longo.

Logo, existe a necessidade de se identificar precocemente plantas variantes somaclonais ainda no cultivo antes que os mesmos sejam disponibilizados ao produtor, facilitando assim somente o acesso a bananeiras comercialmente produtivas. Desta forma o objetivo do presente trabalho foi averiguar os caracteres morfológicos da epiderme foliar para caracterizar os cultivares micropropagados de 'Prata-anã' em relação aos seus variantes somaclonais que apresentam a característica gigantismo.

\section{Material e métodos}

Foram utilizadas bananeiras micropropagadas repicadas a partir de variantes somaclonais previamente determinados e de plantas sem sintomas de variação, de acordo com as características morfológicas como altura das plantas. Como se tratavam de três plantas variantes distintas foram designadas PI, PII e PIII, sendo as não-variantes designadas PA - 'Prata-anã'.

Os explantes de bananeira foram repicados em condições assépticas utilizando-se o meio apropriado B2 (MS sais, MS vitaminas, $3 \%$ sacarose, 3 a $5 \mathrm{mg} \mathrm{L}^{-1}$ BAP, $5 \mathrm{~g} \mathrm{~L}^{-1}$ ágar, $\mathrm{pH}$ 5,7) por períodos entre 30 e 60 dias, a fim de multiplicar o número de clones. A temperatura da sala de crescimento estava condicionada entre $27-28{ }^{\circ} \mathrm{C}$ e luz constante. Para induzir o enraizamento, os explantes propagados no meio de multiplicação B2 foram transferidos para o meio de enraizamento B3 (MS vitaminas, MS sais, 3\% sacarose, 0,5 $\mathrm{mg} \mathrm{L}^{-1} \mathrm{NAA}, 5 \mathrm{~g} \mathrm{~L}^{-1}$ ágar e $\mathrm{pH} 5,7$ ). Com aproximadamente 7-10 dias, os explantes já apresentavam sistema radicular.

Após estabelecimento do sistema radicular in vitro, as plântulas foram aclimatizadas em substrato comercial (Empresa Vida Verde Ltda.), e mantidas no setor de Fisiologia Vegetal da Universidade Federal de Lavras. Sendo assim denominado material in vivo.

Realizaram-se cortes a mão livre na região mediana das folhas de bananeiras tanto in vitro quanto in vivo, previamente lavadas em água corrente. Amostras de folhas com $2 \mathrm{~cm} / 2 \mathrm{~cm}$ foram imersas em 
solução fixativa Karnovsky (1965) modificado: glutaraldeído 2,5\%, formaldeído $2 \%$ em tampão cacodilato de sódio $0,05 \mathrm{M}, \mathrm{pH} 7,2$ por um período de 24 horas. Em seguida, foram lavados em tampão cacodilato (três vezes de $10 \mathrm{~min}$ ), pós-fixados em solução de tetróxido de ósmio $1 \%$ em água por 1 hora e subseqüentemente lavados 3 vezes em água destilada, seguida da desidratação em série de acetona $(25,50$, 75,90 uma vez cada e $100 \%$ por três vezes). Posteriormente, as amostras foram levadas para o aparelho de ponto crítico para completar a secagem. Os espécimes obtidos foram montados em suportes de alumínio stubs, com fita de carbono dupla face colocada sobre uma película de papel alumínio, cobertos com ouro e observados em microscópio eletrônico de varredura LEO EVO 40XVP. Diversas imagens para cada amostra foram geradas e registradas digitalmente, em aumentos variáveis, nas condições de trabalho de $20 \mathrm{Kv}$ e distância de $9 \mathrm{~mm}$.

Os resultados obtidos nessas avaliações foram submetidos à análise de variância e as médias foram comparadas através do teste de Tukey ao nível de 5\% de probabilidade.

\section{Resultados e discussão}

O número médio de estômatos, bem como os dados relativos aos diâmetros polares e equatoriais dos mesmos na cultivar Prata-anã não-variante e variante são apresentados na (Tab. 1).

Como pode ser observado houve diferença significativa $(\mathrm{P}<0,01)$ entre o diâmetro polar da 'Prata-anã' não variante e suas variantes in vitro. Verifica-se também que o número médio de estômatos é relativamente menor nas plantas variantes somaclonais, porém sem diferenças significativas a não ser para a planta PIII.
Tanto as plantas variantes e não-variantes somaclonais apresentam ausência total de tricomas (Fig. 1-4). As superfícies abaxiais e adaxiais se distinguem quanto ao número e a posição dos estômatos em relação às células epidérmicas. A superfície adaxial apresenta um número bastante reduzido de estômatos, parecendo estes estarem dispostos em um plano diferente das células epidérmicas, demonstrando certa concavidade. No entanto, nenhuma dessas características difere nas plantas variantes das nãovariantes.

Os estômatos de todas as amostras foram classificados como do tipo tetracítico (Fig. 1-9), sendo confirmada por microscopia fotônica (dados não demonstrados). Pode também ser observado na superfície abaxial da folha da cultivar Prata-anã nãovariante (Fig. 1,2), estômatos enfileirados de maneira uniforme e linear, enquanto na superfície abaxial da cultivar Prata-anã variante (Fig. 3, 4), os estômatos são distribuídos de forma ondular. São notadas nitidamente a regularidade da cera para as amostras não variantes (Fig. 1,2), enquanto as amostras variantes apresentam cera descamada e irregular (Fig. 3, 4).

Na superfície abaxial observa-se o estômato em evidência das folhas da cultivar Prata-anã não-variante (Fig. 5) e a variante (Fig. 6), ambas sob condição in vivo e o estômato das plantas não-variante (Fig. 7) e variantes (Fig. 8, 9) sob condição in vitro. A descamação de cera é evidente somente nas plantas variantes de ambos os materiais (in vitro e in vivo) podendo atuar dessa forma como marcador morfoanatômico.

Diferenças nas ceras podem estar relacionadas aos constituintes da cutícula foliar, que de acordo com Albert \& Filho (2002), podem ser divididos em componentes hidrofóbicos (cera), semi-hidrofóbicos (cutina) e hidrófilos (pectinas e celulose). Então, se a

Tabela 1. Valores médios da freqüência estomática e medidas dos diâmetros polares e equatoriais de estômatos na epiderme abaxial de folhas de plantas não-variantes e variantes de bananeira (Musa sp. Colla) cultivar Prata-anã.

\begin{tabular}{|c|c|c|c|c|c|c|}
\hline \multirow[t]{2}{*}{ Prata-anã } & \multicolumn{2}{|c|}{$\begin{array}{l}\text { Número médio de estômatos } \\
\qquad\left(\mathrm{mm}^{2}\right)\end{array}$} & \multicolumn{2}{|c|}{$\begin{array}{l}\text { Diâmetro Polar } \\
\qquad(\mu \mathrm{m})\end{array}$} & \multicolumn{2}{|c|}{$\begin{array}{l}\text { Diâmetro equatorial } \\
\qquad(\mu \mathrm{m})\end{array}$} \\
\hline & In vitro & In vivo & In vitro & In vivo & In vitro & In vivo \\
\hline PA - não variante & $126,78 \mathrm{a}$ & $159,51 \mathrm{a}$ & $33,13 \mathrm{a}$ & $31,38 \mathrm{ab}$ & $34,83 \mathrm{a}$ & $30,95 b$ \\
\hline PI - variante 1 & $110,11 \mathrm{a}$ & $145,82 \mathrm{a}$ & $30,99 b$ & $32,73 a$ & $28,17 b$ & $37,75 a$ \\
\hline PII - variante 2 & $108,92 \mathrm{a}$ & $116,66 \mathrm{a}$ & $28,80 \mathrm{c}$ & $31,74 \mathrm{ab}$ & $29,41 b$ & $33,32 b$ \\
\hline PIII - variante 3 & $64,28 b$ & $104,75 b$ & $28,12 \mathrm{c}$ & $29,41 b$ & $34,83 \mathrm{a}$ & $31,48 b$ \\
\hline
\end{tabular}

* Médias seguidas de letras distintas na coluna diferem entre si pelo Teste de Tukey, a 5\% de probabilidade. 

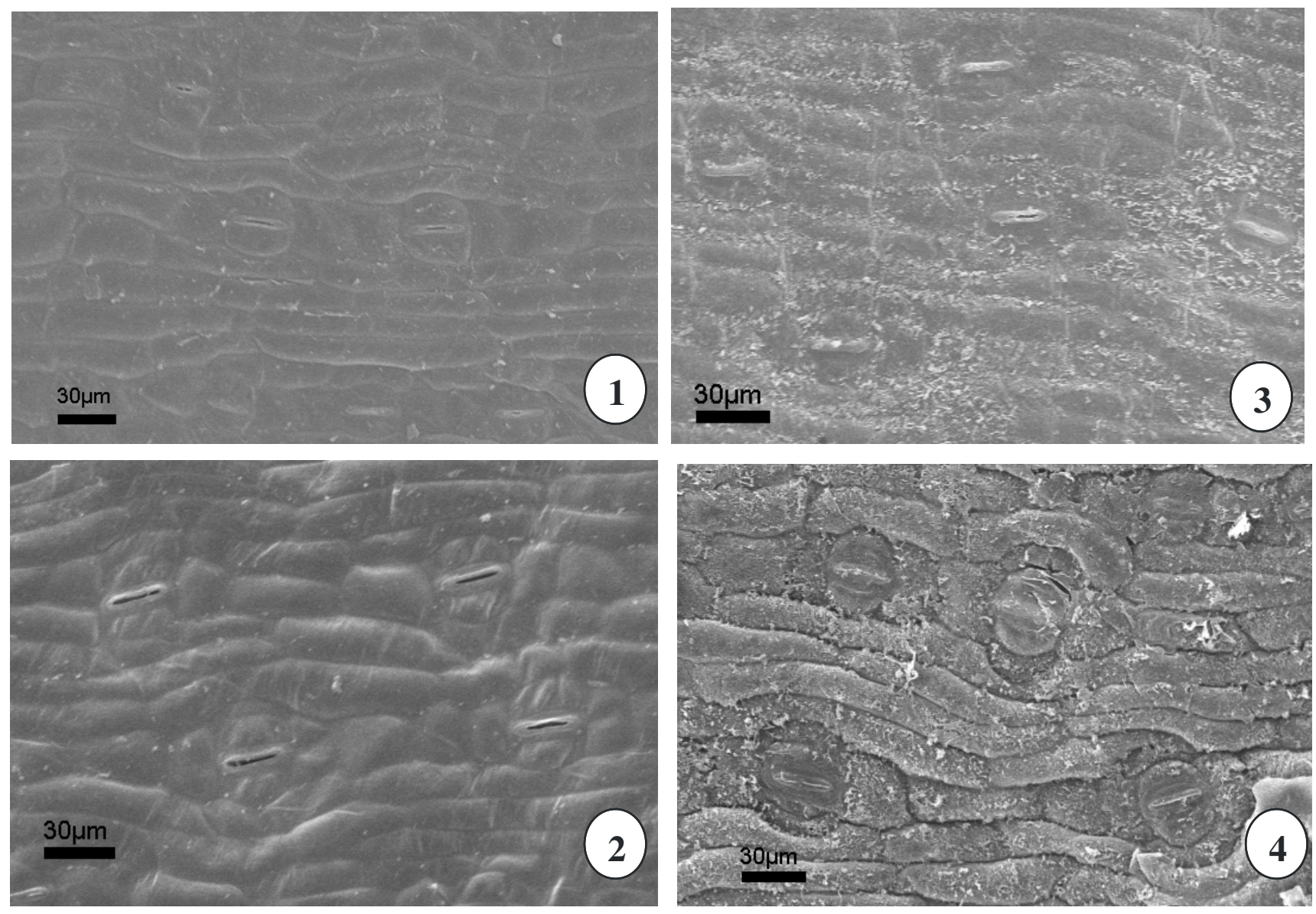

Figuras 1-4. Eletromicrografia de varredura de estômatos da superfície abaxial das folhas de bananeiras (Musa sp. Colla) da cultivar Prata-anã cultivadas sob condição: 1. in vitro e 2. in vivo de plantas não varinates. 3. Condição in vitro e 4. in vivo de plantas variantes somaclonais para característica gigantismo.

cera é um componente hidrofóbico sua função está relacionada ao controle da evaporação. Como exemplo, a cutícula em condições áridas funciona como uma membrana extracelular em toda a área foliar promovendo uma barreira entre a planta e o meio ambiente, agindo primariamente como uma barreira contra a evaporação excessiva (Cameron et al. 2006). Dessa forma se esperaria ausência de cera nas plantas somente sob condição in vitro. Porém, tanto as bananeiras cultivadas in vitro quanto in vivo apresentaram diferenças quanto à regularidade das ceras nas plantas variantes (Fig. 1,2) que se apresenta uniformemente distribuída, não sofrendo as descamações observadas nas não-variantes (Fig. 3, 4) o que indica que estas características se mantém como marcador morfoanatômico da variação somaclonal.

Segundo Cameron et al. (2006), as ceras cuticulares consistem de séries homólogas de longas cadeias de ácidos graxos, álcoois, aldeídos, alcanos, ésteres e compostos orgânicos cíclicos. Estes concordam com outros autores ao afirmar uma correlação indicando que o aumento da cera reduziria a condutância epidérmica de algumas plantas. Da mesma forma a diminuição da cera aumentaria a condutância.

Estudos em coníferas sugerem que mudanças na morfoanatomia foliar continuam além de maturidade reprodutiva (Apple et al. 2002; Day et al. 2001; Koch et al. 2004; Richardson et al. 2000). Ao se comparar o incremento de cera entre as células epidérmicas de Eucalyptus regnans F. Muell verificou-se oclusões da câmara estomática e aumento relacionado à idade e altura da árvore (England \& Attiwill 2006). Mençoes sobre o comportamento da cera em plantas herbáceas como a bananeira e sua correlação com a variação somaclonal ainda não haviam sido descritos na literatura. Sendo que as condições de amostragem do material in vitro e in vivo ocorreram com plantas de mesmo tempo de repicagem e propagação, os 

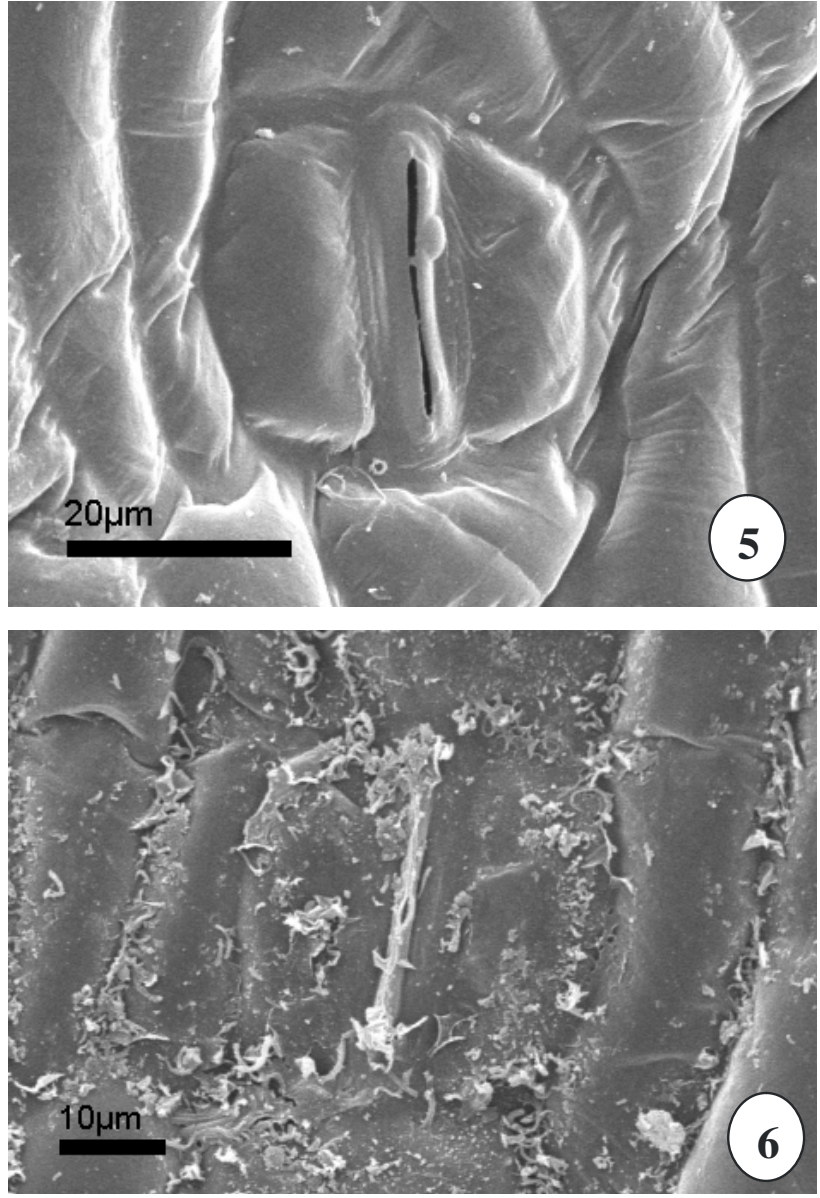

Figuras 5-6. Eletromicrografia de varredura de estômatos da superfície abaxial das folhas de bananeiras (Musa sp. Colla) da cultivar Prata-anã cultivadas sob condição in vivo. 5. Cera regular e uniforme da planta não-variante. 6. Cera irregular e escamada da planta variante somaclonal para característica gigantismo.

resultados aqui obtidos apresentam-se como possíveis localizadores de diferenças fenotípicas.

Simmonds \& Dodds (1949), verificou o efeito da poliploidia em famílias de plântulas de bananeiras produzidas por retrocruzamento de três híbridos diplóides, obtidos por cruzamentos de duas espécies diplóides. Alguns pentaplóides foram produzidos e apresentavam estômatos maiores e densidades menores que os triplóides. Por sua vez os triplóides possuíam estômatos um pouco maiores que os diplóides. Além da contagem do número de cromossomos, a análise dos estômatos mostrou ser uma boa medida do grau de poliploidia das plantas. O que justifica a procura de um marcador morfoanatômico, como no caso deste trabalho.

O diâmetro polar dos estômatos mostrou-se como um bom marcador morfológico diferenciando o material in vitro, porém o mesmo não foi observado com as amostras in vivo. A maior quantidade de cera presente nas plantas variantes tanto in vitro como in vivo, demonstram também a possibilidade de serem marcadores morfoanatômicos. Tornam-se necessários estudos fisiológicos que expliquem o processo de evaginação da abertura estomática observada nas plantas variantes in vitro.
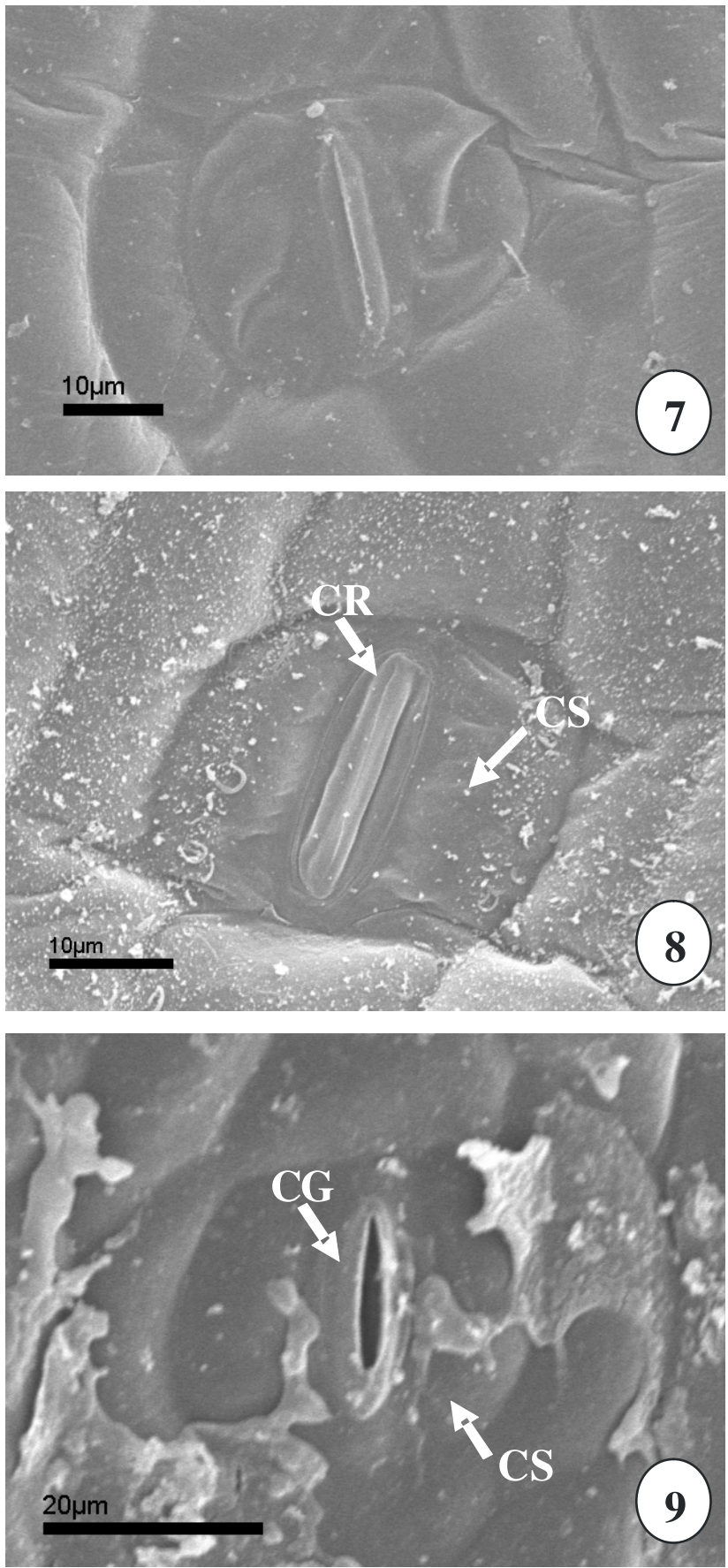

Figuras 7-9. Eletromicrografia de varredura de estômatos da superfície abaxial das folhas de bananeiras (Musa sp. Colla) da cultivar Prata-anã cultivadas sob condição in vitro. 7 . Cera regular e uniforme da planta não-variante. 8-9. Cera irregular e escamada da planta variante somaclonal para característica gigantismo. CS - célula subsidiária, CG - célula-guarda e CR - crista estomática. 
Conclui-se que os caracteres morfoanatômicos da epiderme foliar, como densidade estomática, diâmetro estomático polar e a uniformidade da cera atuam como marcadores morfológicos para caracterizar os cultivares micropropagados de 'Prata-anã' em relação aos seus variantes somaclonais que apresentam a característica gigantismo.

\section{Agradecimentos}

A Mutiplanta Tecnologia Vegetal, na pessoa do Dr. Marcos Paiva, pelo fornecimento do material biológico; à técnica do Laboratório de Microscopia Eletrônica da Universidade Federal de Lavras, Eloísa Aparecida das Graças Leite Lopes, pelo auxílio nas análises.

\section{Referências bibliográficas}

Albert, L.H.B. \& Filho, R.V. 2002. Características morfológicas da cutícula foliar e efeitos de adjuvantes no controle químico de três espécies de Guanxumas. Ciência e Agrotecnologia 26: 888-899.

Álvares, M.C. \& Caldas, L.S. 2002. Crescimento, produção e variação somaclonal em bananeiras micropropagadas. Pesquisa Agropropecuária Brasileira 37: 415-420.

Apple, M.; Tiekotter, K.; Snow, M.; Young, J.; Tingey, D.; Soeldner, A. \& Bond, B.J. 2002. Needle anatomy varies with increasing tree age in Douglas-fir. Special Issue: Age-Related Change in Structure and Function of Trees and Forests in the Pacific Northwest. Tree Physiology 22: $181-189$

Cameron, K.D.; Teece, M.A. \& Smart, L.B. 2006. Increased accumulation of cuticular wax and expression of lipid transfer protein in response to periodic drying events in leaves of tree tobacco. Plant Physiology 140: 176-183.
Day, M.E.; Greenwood, M.S. \& White, A.S. 2001. Age-related changes in foliar morphology and physiology of red spruce and their influence on declining phtosynthetic rates and productivity with tree age. Tree Physiology 21: 1195-1204.

Damasco, O.P.; Graham, G.C.; Henry, R.J.; Adkins, S.W.; Smith, M.K. \& Godwin, I.D. 1996. Random amplified polimorphic DNA (RAPD) detection of dwarf off-types in micropropagated Cavendish (Musa spp. AAA) bananas. Plant Cell Reports 16: 118-123.

England, J.R. \& Attiwill, P.M. 2006. Changes in leaf morphology and anatomy with tree age and height in the broadleaved evergreen species, Eucalyptus regnans F. Muell. Trees - Structure and Function 20: 79-90.

Karnovsky, M.J. 1965. A formaldehyde-glutaraldehyde fixative of high osmalarity for use in eletron miscroscopy. Journal of Cell Biology 27: 137A-138A.

Koch, G.W.; Sillett, S.C.; Jennings, G.M. \& Davis, S.D. 2004. The limits of tree height. Nature 428: 851-854

Santos, C.C. \& Rodrigues, P.H.V. 2004. Variação somaclonal em mudas micropropagadas de bananeira, cultivar Pacovan. Bragantia 63: 201-205.

Simmonds, N.W. \& Dodds, K.S. 1949. Meiose in seeded diploids of Musa. Journal of Genetics 49: 221-225.

Smith, M.K. 1988. A review of factors influencing the genetic stability of micropropagated bananas. Fruits 43: 210-223.

Souto, R.F.; Rodrigues, M.G.V.; Alvarenga, C.D.; Silva, J.T.A. Maeno, P.; Gonzaga, V. 1997. Sistema de produção da Bananeira-prata-anã no norte de Minas Gerais. Belo Horizonte, EPAMIG.

Souza, A.S.; Dantas, J.L.L.; Souza, F.V.D.; Cordeiro, Z.J.M. \& Neto, S.P.S. 1999. Propagação. Pp. 151-195. In: E.J. Alves (org.). A cultura da banana: aspectos técnicos, socioeconômicos e agroindustriais. $2^{\mathrm{a}} \mathrm{ed}$. Rev. Brasília, EMBRAPA-CNPMF.

Richardson, A.D.; Berlyn, G.P.; Ashton, P.M.S.; Thadani, R. \& Cameron, I.R. 2000. Foliar plasticity of hybrid spruce in relation to crown position and stand structure. Canadian Journal of Botany 78: 305-317. 